\title{
Ubiquitin C-terminal hydrolase isozyme L1 is associated with shelterin complex at interstitial telomeric sites
}

\author{
Aleksandar Ilic', Sumin Lu', Vikram Bhatia', Farhana Begum², Thomas Klonisch², Prasoon Agarwal', Wayne Xu \\ and James R. Davie ${ }^{1 *}$ (I)
}

\begin{abstract}
Background: Ubiquitin C-terminal hydrolase isozyme L1 (UCHL1) is primarily expressed in neuronal cells and neuroendocrine cells and has been associated with various diseases, including many cancers. It is a multifunctional protein involved in deubiquitination, ubiquitination and ubiquitin homeostasis, but its specific roles are disputed and still generally undetermined.

Results: Herein, we demonstrate that UCHL1 is associated with genomic DNA in certain prostate cancer cell lines, including DU 145 cells derived from a brain metastatic site, and in HEK293T embryonic kidney cells with a neuronal lineage. Chromatin immunoprecipitation and sequencing revealed that UCHL1 localizes to TTAGGG repeats at telomeres and interstitial telomeric sequences, as do TRF1 and TRF2, components of the shelterin complex. A weak or transient interaction between UCHL1 and the shelterin complex was confirmed by immunoprecipitation and proximity ligation assays. UCHL1 and RAP1, also known as TERF2IP and a component of the shelterin complex, were bound to the nuclear scaffold.
\end{abstract}

Conclusions: We demonstrated a novel feature of UCHL1 in binding telomeres and interstitial telomeric sites.

Keywords: UCHL1, Shelterin complex, Interstitial telomeric sites, Prostate cancer

\section{Background}

Ubiquitin C-terminal hydrolase isozyme L1 (UCHL1) is a highly conserved protein, abundant in neurons-making up $1-2 \%$ of total brain protein - and present at lower concentrations in neuroendocrine cells [1]. Despite the fact that UCHL1 has been linked with neurodegenerative diseases and a wide range of cancers, its physiological role remains elusive [2]. UCHL1 hydrolyzes small C-terminal adducts of ubiquitin to generate free monomeric ubiquitin. However, its activity is low compared to that of other deubiquitinating enzymes, and whether it is a true hydrolase enzyme is a matter of debate [1,3-5]. Conversely, UCHL1 was shown to protect the protein NOXA

\footnotetext{
${ }^{*}$ Correspondence: jim.davie@umanitoba.ca

${ }^{1}$ Children's Hospital Research Institute of Manitoba, University

of Manitoba, 715 McDermot Avenue, Room 600A, Winnipeg, MB R3E 3P4, Canada

Full list of author information is available at the end of the article
}

(also called PMAIP1) from proteasomal degradation by removing K48-linked polyubiquitin chains [6]. Similarly, p53, HIF- $1 \alpha$ and EGFR are thought to escape turnover as a result of UCHL1 hydrolase activity [7-9]. In vitro studies have suggested that UCHL1 has a dimerizationdependent ubiquitin ligase function [10]. This ubiquitination function was reported to cause the destabilizing effect of UCHL1 on SMN and MDM2 proteins $[9,11]$. In neurons, UCHL1 may affect ubiquitin homeostasis by stabilizing monoubiquitin, and this role is independent of UCHL1 hydrolase or ligase functions [12].

Although UCHL1 is strongly expressed in neurons, it is also present at high levels in many non-neuronal tumors, implicating that UCHL1 is an oncogene. However, this is not generally applicable as the UCHL1 gene can be silenced via promoter hypermethylation in some tumors, suggesting a potential suppressor function for UCHL1 in certain tumors [13]. In the case of prostate 
cancer, comparative proteomic data from prostate cancer cell lines showed that UCHL1 was expressed in androgen insensitive cell lines [14]. Furthermore, UCHL1 knockdown studies on the androgen insensitive DU 145 cell line demonstrated that UCHL1 promotes prostate cancer metastasis by the induction of epithelial-to-mesenchymal transition (EMT) [15]. Knockdown of UCHL1 in HEK293T cells attenuated the expression of genes involved in proliferation and migration and increased expression of genes involved in apoptosis and cell cycle arrest [16].

In this study, we analyzed the proteins cross-linked to nuclear DNA by cisplatin in situ in a panel of human prostate cancer cell lines derived from benign hyperplasia or various metastatic sites. We identified UCHL1 as a protein cross-linked to DNA in some of the prostate cancer cells, including DU 145, derived from brain metastasis. To explore the UCHL1 role, we examined its genomic distribution and its association with proteins binding the same DNA sequence motif or DNA structure.

\section{Results}

\section{Identification of UCHL1 as a DNA-associated protein}

To identify proteins differentially bound to genomic DNA in human prostate cancer cell lines, we compared the two-dimensional gel patterns of proteins crosslinked to genomic DNA with cisplatin. The prostate cell lines under study were $\mathrm{BPH}-1$ from benign hyperplasia, androgen receptor-positive $\mathrm{LNCaP}$ derived from a metastatic lymph node site, androgen receptor-negative DU 145 and PC-3 derived from metastatic brain and bone sites, respectively. Proteins cross-linked to DNA in cells with cisplatin were captured on hydroxyapatite. ProteinDNA cross-links were reversed with thiourea, and the proteins were isolated and resolved by two-dimensional polyacrylamide gel electrophoresis (PAGE) (Fig. 1a). We identified the lamins $\mathrm{A} / \mathrm{C}$ as proteins cross-linked by cisplatin in the four cell lines (Fig. 1b). The identity of the proteins that were differentially cisplatin cross-linked in the prostate benign and cancer cell lines was determined by mass spectrometry (in-gel digestion, nanoliquid chromatography and tandem mass spectrometry). Spot 2 was found in prostate cancer preparations, but much less so in the benign BPH-1 cell preparation (Fig. 1a). Spot 2 was identified as $\mathrm{KH}$-type splicing regulatory protein (KSRP) or far upstream element-binding protein 2 (FUBP2) encoded by the KHSRP gene (Fig. 1c). KSRP/FUBP2 has a molecular mass of $73.1 \mathrm{kDa}$ and $\mathrm{pI}$ of 6.85 .

Spot 16 was among the proteins cisplatin crosslinked to DNA in DU 145 cells, but was absent in BPH1 , LNCaP and PC-3 cells. This protein was identified as UCHL1 which has a molecular mass of $24.8 \mathrm{kDa}$ and a $\mathrm{pI}$ of 5.33 (Fig. 1d).
To verify the identification of proteins in spots 2 and 16 as KSRP/FUBP2 and UCHL1, respectively, immunoblot analyses using anti-KSRP or anti-UCHL1 antibodies were performed on samples of proteins isolated by cross-linking to DNA with cisplatin in human prostate benign and cancer cell lines. HDAC1, which we had previously shown to be cross-linked to DNA by cisplatin or formaldehyde [17], was used as positive control and was also detected by immunoblot. KSRP/FUBP2 was crosslinked to DNA in the prostate cancer cell lines, but not in BPH-1 (Fig. 1c). In contrast, UCHL1 was cross-linked to DNA with cisplatin in DU 145, but not BPH-1, PC-3 and LNCaP cells (Fig. 1d). To determine whether UCHL1 could be cross-linked to nuclear DNA with formaldehyde under ChIP assay conditions, cells were treated with formaldehyde, and proteins cross-linked to DNA were collected after dissociation from hydroxyapatitebound DNA. As with cisplatin cross-linking, UCHL1 was cross-linked to nuclear DNA only in the DU 145 cells (Fig. 1d).

The differential UCHL1 cross-linking among the four cell lines could be due to differences in recruitment or differences in expression of UCHL1. Thus, we determined the cellular expression of UCHL1 in the prostate benign and cancer cell lines. Figure 1d shows that UCHL1 was expressed only in DU 145 cells. Moreover, UCHL1 was not expressed in the LNCaP castration-resistant cell line C4-2 (data not shown) [18]. UCHL1 transcripts were found in DU 145, but not in PC-3 or C4-2 cells (data not shown).

We also tested a panel of PC-3-derived cell lines. The PC3M, PC3-Pro4 and PC3-LN4 cell lines were obtained by injection into the prostate of athymic mice, isolation from prostate and lymph nodes and re-injection into the prostate. These PC-3 lines differ in metastatic potential, with the PC3-LN4 having the greatest metastatic potential [19]. We found that, contrary to the parental PC-3 cell line, these three cell lines expressed UCHL1 (Fig. 1e).

We investigated whether UCHL1-expressing cells in general had UCHL1 associated with nuclear DNA or whether this was a feature unique to DU 145 cells. In all cell lines in which UCHL1 was expressed (PC3M, PC3Pro4 and PC3-LN4), UCHL1 was cross-linked to nuclear DNA by formaldehyde (Fig. 1e). HEK293T cells, which have characteristics of immature neurons [20], were reported to express UCHL1 [16]. Our immunoblot analysis confirmed this finding, but showed that UCHL1 levels were lower in HEK293T than in DU 145 cells (Fig. 1e). In agreement with the above results, UCHL1 was crosslinked to DNA in HEK293T cells. However, we consistently observed that the yield of UCHL1 recovered from formaldehyde-treated HEK293T cells was lower than that from DU 145 cells. 
a

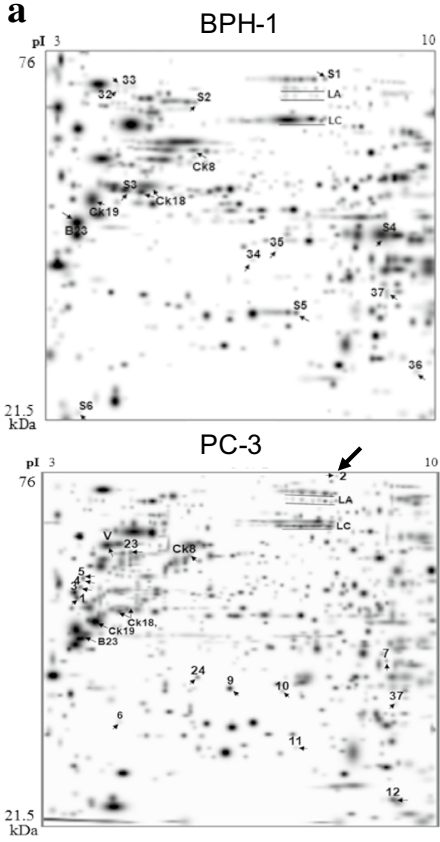

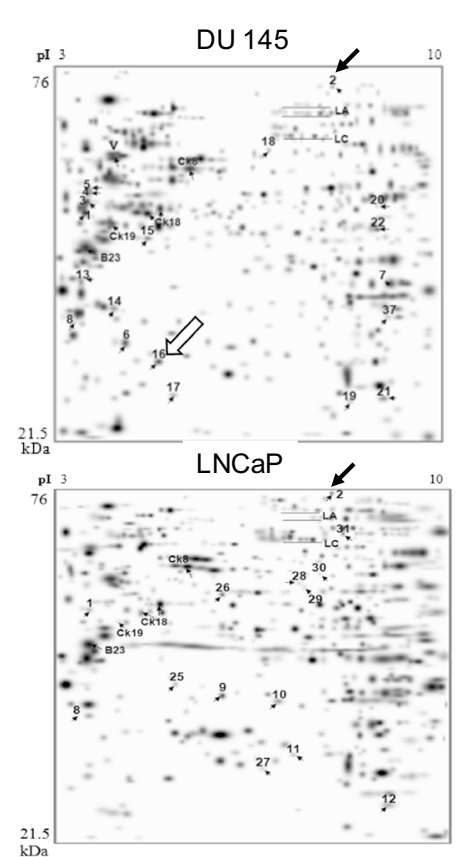

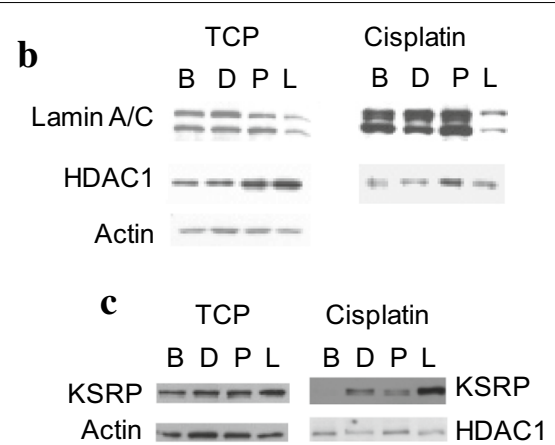

d

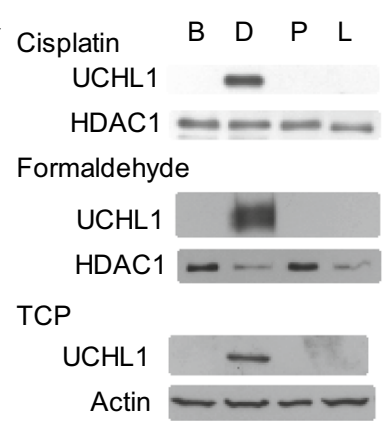

e

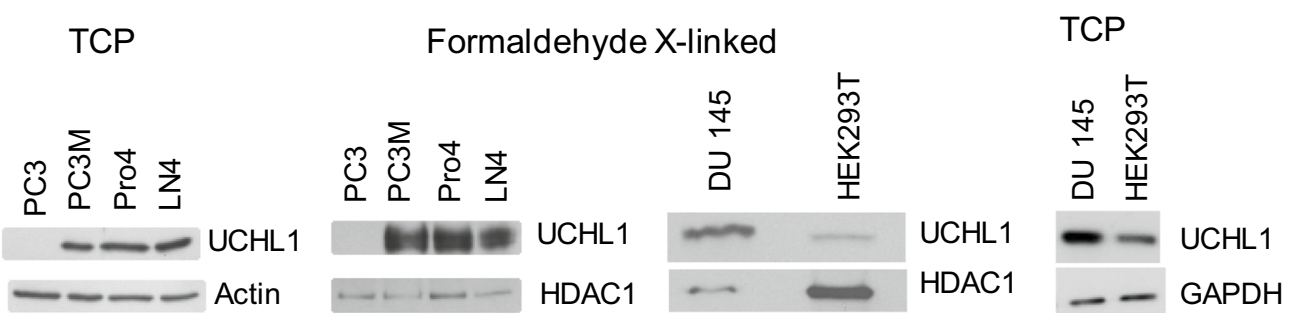

Fig. 1 UCHL1 is associated with genomic DNA in prostate cancer cells expressing it. a DNA cross-linked proteins from BPH-1, DU 145, PC-3 and LNCaP cells treated with $1 \mathrm{mM}$ cisplatin were electrophoretically resolved on two-dimensional PAGE. The gels were stained with silver. b-e Total cellular proteins (TCP) or DNA cross-linked proteins isolated by hydroxyapatite column chromatography from cells treated with $1 \mathrm{mM}$ cisplatin or $1 \%$ formaldehyde were resolved by SDS-10\% PAGE and immunoblotted with indicated antibodies. Cells in b-d were BPH-1 (B), DU 145 (D), PC-3 (P) and LNCaP $(L)$

These results demonstrate that in UCHL1-expressing cells, UCHL1 is associated with nuclear DNA.

\section{Genomic distribution of UCHL1}

To determine the genomic location of UCHL1 in DU 145 cells, we initially performed chromatin immunoprecipitation (ChIP) sequencing (ChIP-seq) with formaldehyde cross-linking and sonication to fragment the DNA (average lengths 200-300 bp). We tested several commercial UCHL1 antibodies for specificity and efficiency in immunoprecipitating UCHL1 under ChIP conditions. The mouse monoclonal anti-UCHL1 antibody (R\&D Systems) was identified to be "CHIP-grade." ChIP-seq and bioinformatic data analyses revealed that the DNA sequences of the UCHL1 peaks were highly repetitive.
These sequences contained a CCC (GGG) repeat every three bases. The UCHL1 ChIP-sequencing was repeated in DU 145 and HEK293T cells with two revisions to the method. First, we used dual cross-linking (DSP and formaldehyde), which we found increased the association of UCHL1 to DNA. Secondly, we fragmented the chromatin with micrococcal nuclease. Significantly, read-enriched positions or peaks were recognized using the MACS software default parameters with a $p$ value threshold of $1 \mathrm{E}-5$ and mfold $(30,10)$. We identified 191 peaks in the two DU 145 UCHL1 ChIP-seq analyses (Additional file 1).

Analyses of the 191 UCHL1 ChIP-seq peaks in DU 145 showed that although UCHL1 binding sites were located on all chromosomes, the UCHL1 peaks were enriched on chromosomes 2, 12, 20, X and Y (Fig. 2a). Most UCHL1 


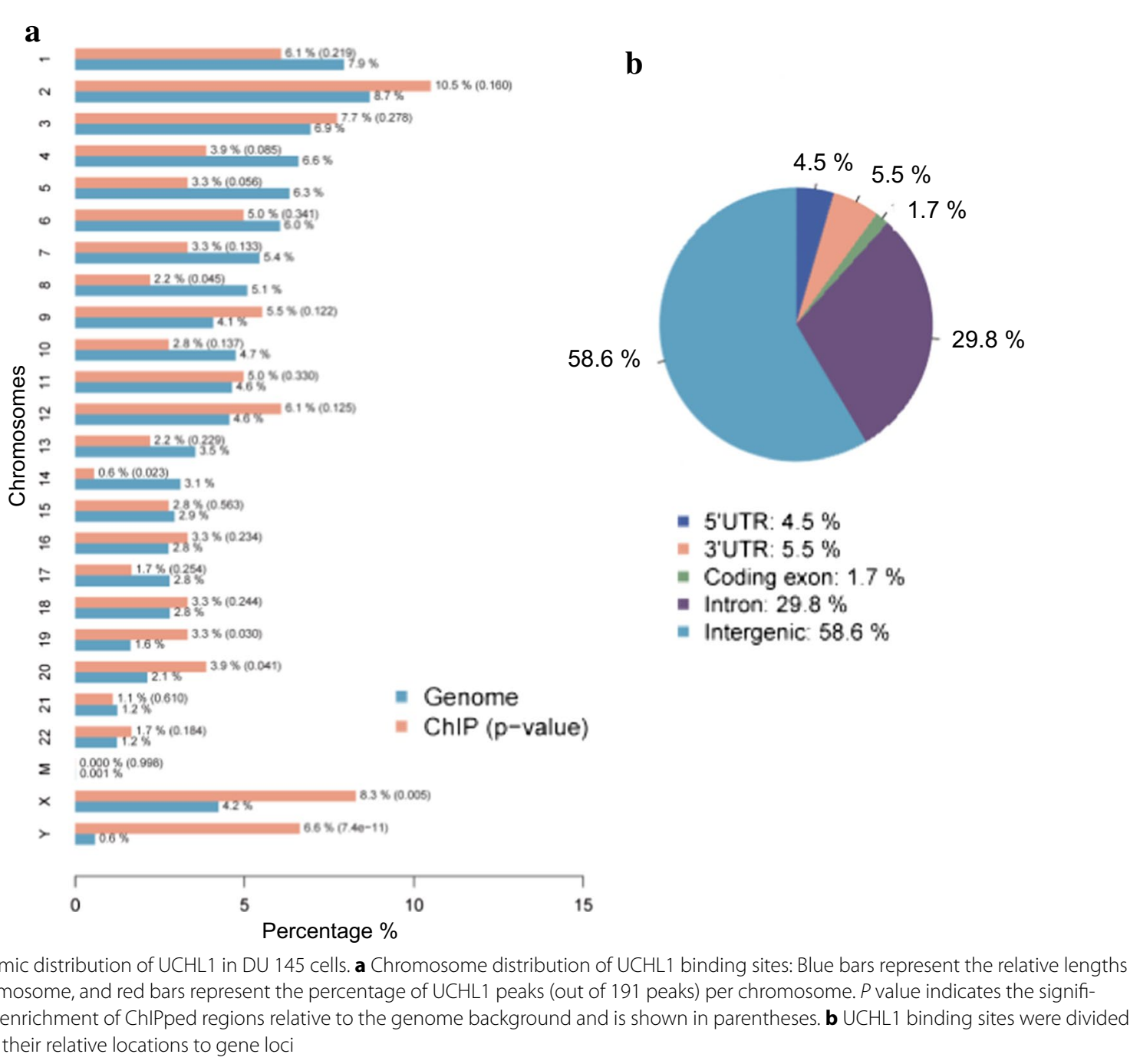

peaks were present in intergenic regions (about 60\%) and introns (about 30\%) (Fig. 2b). Few UCHL1 peaks were found in exons (about 2\%). We identified 76 genes for which the UCHL1 peaks were located within the gene body or $5-\mathrm{Kb}$ up or downstream of the gene (Additional file 2). The functional GO term enrichment of these 76 genes showed several genes with roles in Rho signaling (Additional file 3).

Of the 191 UCHL1 peaks in DU 145 cells, 55 were also detected in HEK293T cells (Additional file 1). In HEK293T cells, the intensity of UCHL1 peaks was lower than in DU 145 cells, consistent with the lower level formaldehyde cross-linking of UCHL1 to HEK293T nuclear DNA (Fig. 1). UCHL1 peaks were identified in the introns of genes coding for CLIC6 (chloride intracellular channel 6), CFDP1 (craniofacial development protein 1), HS3ST4 (heparan sulfate-glucosamine 3-sulfotransferase 4), GPR35 (G protein-coupled receptor 35), DDX11L2 (DEAD/H-box helicase 11 like 2) and the upstream promoter region of the PCGF3 (polycomb group ring finger 3) gene (Fig. 3a). Dual cross-linking ( $1 \mathrm{mM}$ DSP $+0.5 \%$ formaldehyde) assays were applied to validate the UCHL1 binding sites in DU 145 and HEK293T cells. As a control, we also performed the UCHL1 ChIP assays with PC-3 prostate cancer cells which do not express UCHL1. Figure 3b shows the association of UCHL1 to the introns of CLIC6, RASGRF1, HS3ST4, CFDP1 and to the intergenic site at chr10: 3,986,143-3,986,281 in DU 145 and HEK293T cells.

We extracted the sequences of the 191 common peaks for motif analysis, using the MEME program. We found five top significant motifs (Fig. 4a). The UCHL1 peaks often located with the simple repeat (CCCTAA) $n$. 

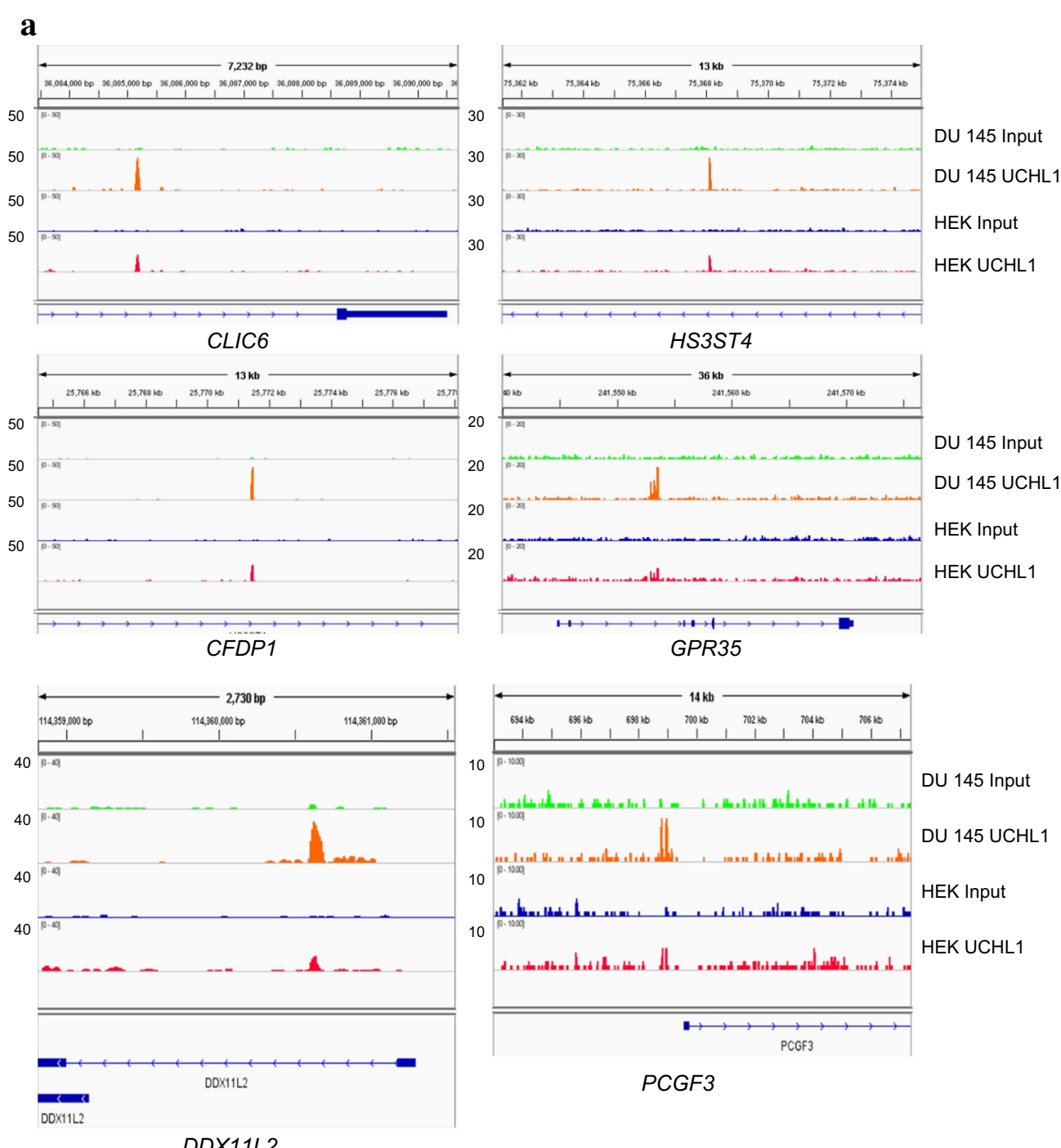

$D D X 11 L 2$

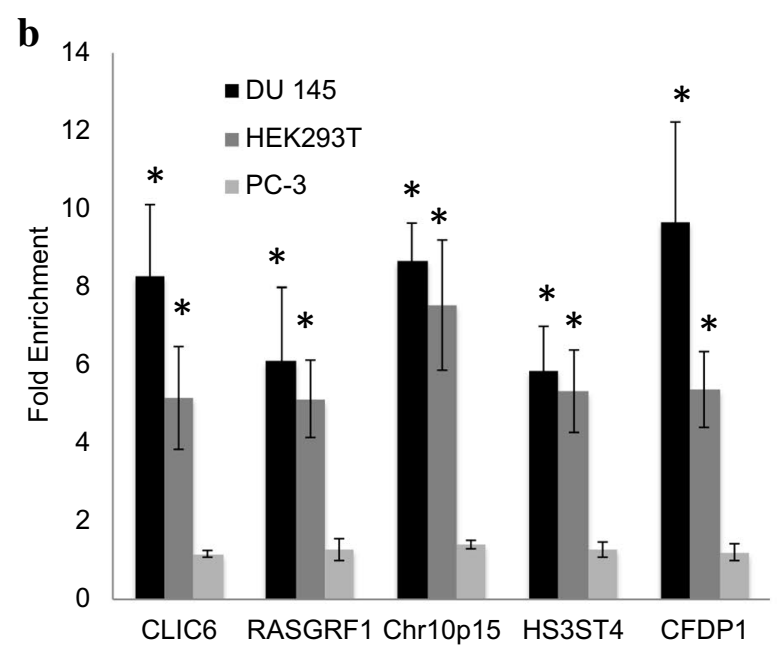

Fig. 3 Representation and validation of random UCHL1 binding sites in DU 145 and HEK293T cells. a Signal tracks showing DNA enrichment in UCHL1 ChIP compared to genomic input. The peak signals were normalized by igvtools. b ChIP experiments were performed using anti-UCHL1 antibodies on DSP/formaldehyde cross-linked 300-400-bp chromatin fragments obtained by sonication from DU 145, HEK293T or PC-3 cells. Fold enrichment values were normalized to IgG ChIP values. Asterisk $\left(^{*}\right)$ indicate statistical significance $p<0.05$ 
a

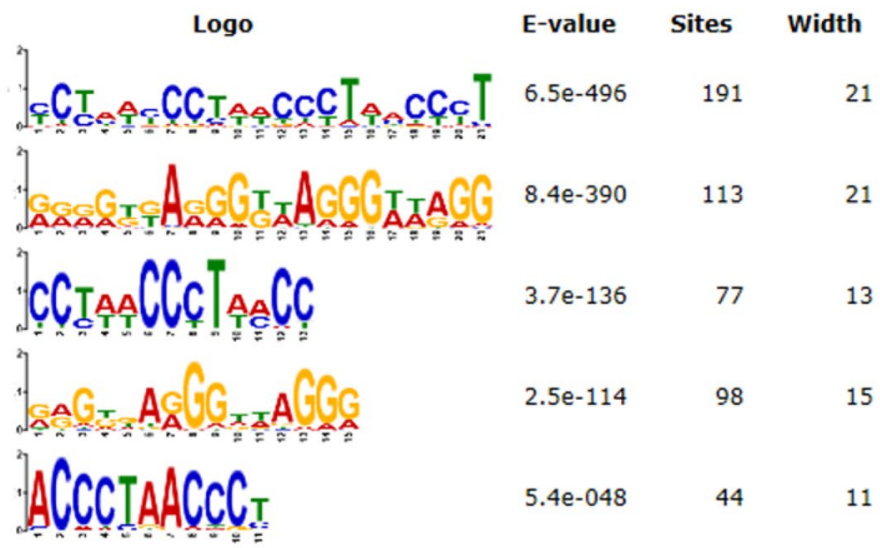

b

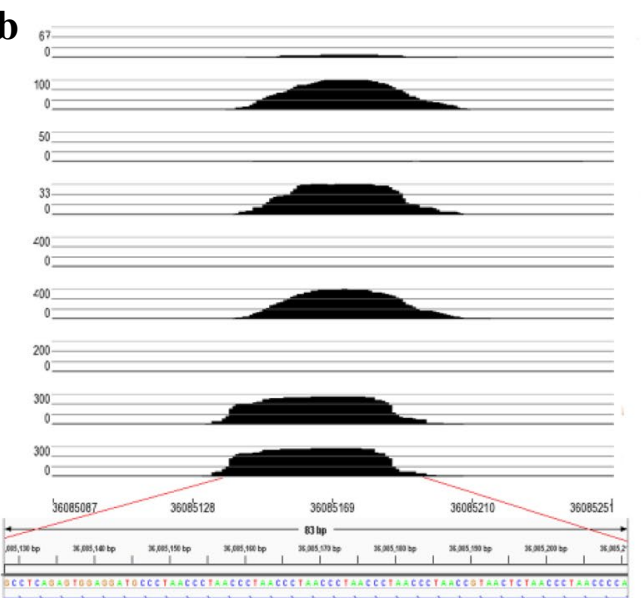

CLIC6

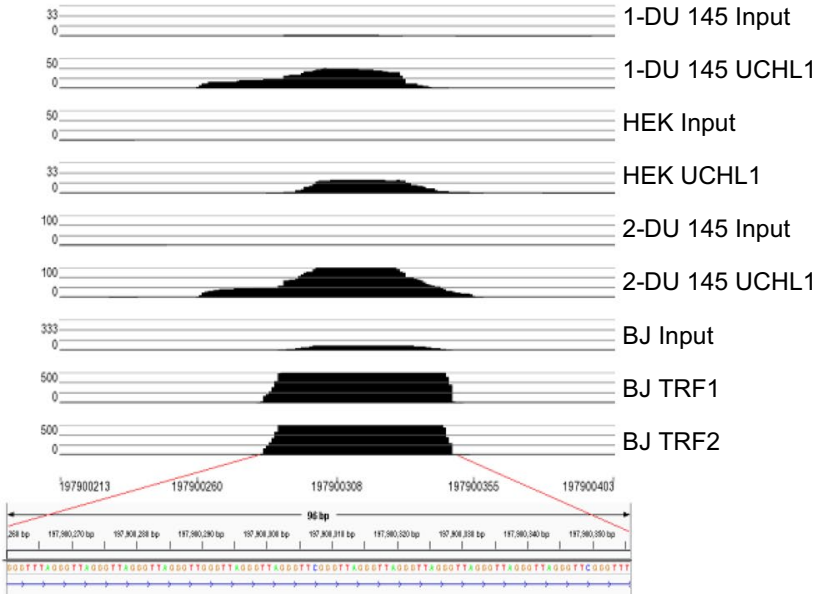

FAM157A

Fig. 4 UCHL1 localizes to telomeric repeat sequences as do TRF1 and TRF2. a The top five motifs were identified using the MEME software. The $E$ value is the expected number of hits by chance (the lower the $E$ value the more significant is the motif). $\mathbf{b}$ Signal tracks showing DNA enrichment in UCHL1 ChIP from DU 145 and HEK293T cells and TRF1 or TRF2 ChIP from BJHELTRas ${ }^{\mathrm{mc}}$ cells (Simonet et al. [21] -21423270) were aligned for CLIC6 and FAM157A genes. Cells were treated with formaldehyde (1-DU 145 Input and UCHL1, HEK Input and UCHL1) or DSP/formaldehyde (2-DU 145 Input and UCHL1)

UCHL1 is associated with the shelterin complex

As there is no evidence that UCHL1 binds DNA directly, we surmised that UCHL1 was associating with a DNAbinding protein that was recognizing the UCHL1 motif. The sequences of UCHL1 binding sites on genes DDX11L2 and PCGF3 were extracted and searched against PROMO (TRANSFC database version 8.3). We found that the TRF1 (telomeric repeat binding factor 1) binds to the sequence underlying the UCHL1 peaks. TRF1 is part of the shelterin complex along with TRF2, TIN2, TPP1, POT1 and RAP1 (telomeric repeat binding factor 2-interacting protein 1, also known as TERF2IP).

Using the publicly available TRF1 and TRF2 ChIP-seq data (GEO Series accession number GSE26005) [21], we show in Fig. 4b that several DNA regions associated with the UCHL1 binding sites in DU 145 and HEK293T cells aligned with genomic locations of TRF1 and TRF2 peaks in the BJHELTRas ${ }^{\mathrm{mc}}$ tumor cell line. BJHELTRas ${ }^{\mathrm{mc}}$ are human fibroblasts (BJ) cells rendered tumorigenic by successive retroviral transductions of telomerase, simian virus 40 early region and oncogenic RAS [22]. The 191 UCHL1 common peaks in DU145 share 28 TRF1 peaks, 26 TRF2 peaks, respectively, or 24 TRF1/TRF2 peaks. This provided evidence that UCHL1 localizes to the same genomic locations as the shelterin complex and the underlying sequences of these peaks contained the canonical telomeric repeat sequences, CCCTAA (TTAGGG) found at telomeres and interstitial telomeric 
sites (ITSs). UCHL1 binding sites containing this repeat are summarized in Table 1.

Using a strategy to identify low affinity or transient interactions of proteins with the shelterin complex, UCHL1 was shown to associate with RAP1 in HTC75 cells [23]. In co-immunoprecipitation assays, we observed an interaction, albeit weak, between TRF2 and UCHL1 in DU 145 and HEK293T cells (Fig. 5a).
The interaction between TRF2 and RAP1, used as positive control, was much stronger. We attempted to reverse the order by immunoprecipitating UCHL1 first followed by immunoblotting with RAP1 or TRF2. However, this approach was unsuccessful in showing an interaction between UCHL1 and RAP1 or UCHL1 and TRF2. As a control, we determined the interaction between UCHL1 and p53, which has been demonstrated previously $[9,24]$.

Table 1 List of UCHL1 binding sites containing CCCTAA (TTAGGG) repeats within and 5-kb up or downstream genes in DU 145 cells

\begin{tabular}{|c|c|c|c|c|}
\hline \multirow[t]{2}{*}{ Chr } & \multicolumn{3}{|c|}{ Peak location } & \multirow[t]{2}{*}{ Expression level $^{\mathbf{b}}$} \\
\hline & Start & End & Gene name & \\
\hline chr1 & 10,102 & 10,425 & Intergenic, upstream of DDX $11 \mathrm{~L} 1^{\mathrm{a}}$ & - \\
\hline chr1 & $18,580,820$ & $18,580,945$ & Intron (IGSF21, intron 2 of 9) & - \\
\hline chr2 & $75,299,579$ & $75,299,730$ & Intron (TACR1, intron 2 of 4 ) & - \\
\hline chr2 & $114,360,577$ & $114,360,716$ & Intron (DDX11L2, intron 1 of 2$)^{a}$ & - \\
\hline chr2 & $182,140,505$ & $182,140,611$ & Intron (LOC101927156, intron 3 of 4) & NA \\
\hline chr2 & $241,553,483$ & $241,553,609$ & Intron (GPR35, intron 2 of 5) ${ }^{a}$ & - \\
\hline chr3 & $9,736,179$ & $9,736,298$ & Intron (MTMR14, intron 17 of 17) & ++ \\
\hline chr3 & $159,411,986$ & $159,412,107$ & Intron (SCHIP1, intron 1 of 6 ) & $++/-$ \\
\hline chr3 & $197,900,087$ & $197,900,374$ & Intron (FAM157A, intron 6 of 6$)^{a}$ & - \\
\hline chr3 & $197,901,288$ & $197,901,414$ & Intron (FAM157A, intron 6 of 6$)^{a}$ & - \\
\hline chr4 & 698,901 & 699,003 & Promoter-TSS (PCGF3) & ++ \\
\hline chr 5 & $82,811,907$ & $82,812,020$ & Intron (VCAN, intron 6 of 12) ${ }^{a}$ & - \\
\hline chr6 & 147,601 & 147,760 & Intron (LINC00266-3, intron 1 of 2 & NA \\
\hline chr6 & $38,912,686$ & $38,912,816$ & Intron (DNAH8, intron 79 of 92) & - \\
\hline chr6 & $161,866,788$ & $161,866,892$ & Intron (PARK2, intron 8 of 10 ) & - \\
\hline chr9 & 10,007 & 10,127 & Intergenic, upstream of DDX $11 \mathrm{~L}^{\mathrm{a}}$ & NA \\
\hline chr9 & 10,153 & 10,269 & Intergenic, upstream of DDX $11 \mathrm{L5}^{\mathrm{a}}$ & NA \\
\hline chr9 & 10,288 & 10,403 & Intergenic, upstream of DDX $11 \mathrm{~L}^{\mathrm{a}}$ & NA \\
\hline chr9 & $2,824,012$ & $2,824,113$ & Intron (KIAA0020, intron 11 of 17) & ++ \\
\hline chr9 & $141,054,226$ & $141,054,361$ & Intron (TUBBP5, intron 1 of 4$)^{\mathrm{a}}$ & + \\
\hline chr10 & $4,111,307$ & $4,111,412$ & Intron (LOC101927964, intron 1 of 3) & NA \\
\hline chr12 & $22,393,946$ & $22,394,047$ & Intron (ST8SIA1, intron 3 of 3 ) & - \\
\hline chr15 & $42,243,142$ & $42,243,265$ & Intron (EHD4, intron 2 of 5) & +++ \\
\hline chr16 & 59,970 & 60,077 & Intergenic, upstream of DDX11L10 & - \\
\hline chr16 & $25,771,380$ & $25,771,526$ & Intron (HS3ST4, intron 1 of 1$)^{a}$ & - \\
\hline chr16 & $75,368,040$ & $75,368,166$ & Intron (CFDP1, intron 5 of 6 ) & ++ \\
\hline chr16 & $88,946,595$ & $88,946,716$ & Intron (CBFA2T3, intron 9 of 10) & - \\
\hline chr18 & 10,273 & 10,379 & Intergenic, upstream of LOC102723376 & NA \\
\hline chr20 & $10,172,151$ & $10,172,266$ & Intron (SNAP25-AS1, intron 2 of 4) ${ }^{a}$ & NA \\
\hline chr20 & $62,918,067$ & $62,918,182$ & Intergenic, upstream of LINC00266-1 ${ }^{\mathrm{a}}$ & - \\
\hline chr20 & $62,918,353$ & $62,918,469$ & Intergenic, upstream of LINC00266-1 ${ }^{a}$ & - \\
\hline chr20 & $62,918,583$ & $62,918,739$ & Intergenic, upstream of LINC00266-1 ${ }^{a}$ & - \\
\hline chr21 & $36,085,122$ & $36,085,247$ & Intron (CLIC6, intron 5 of 5) & - \\
\hline chr21 & $45,851,799$ & $45,851,900$ & Intron (TRPM2, intron 27 of 31) & + \\
\hline chr22 & $45,022,364$ & $45,022,483$ & Intergenic, upstream of LINC00229 & - \\
\hline
\end{tabular}

a Identifies binding sites also detected in HEK293T cells

${ }^{b}$ Expression levels in DU 145 cells were extracted from NCBI GEO GSE71756 and GSE71208 


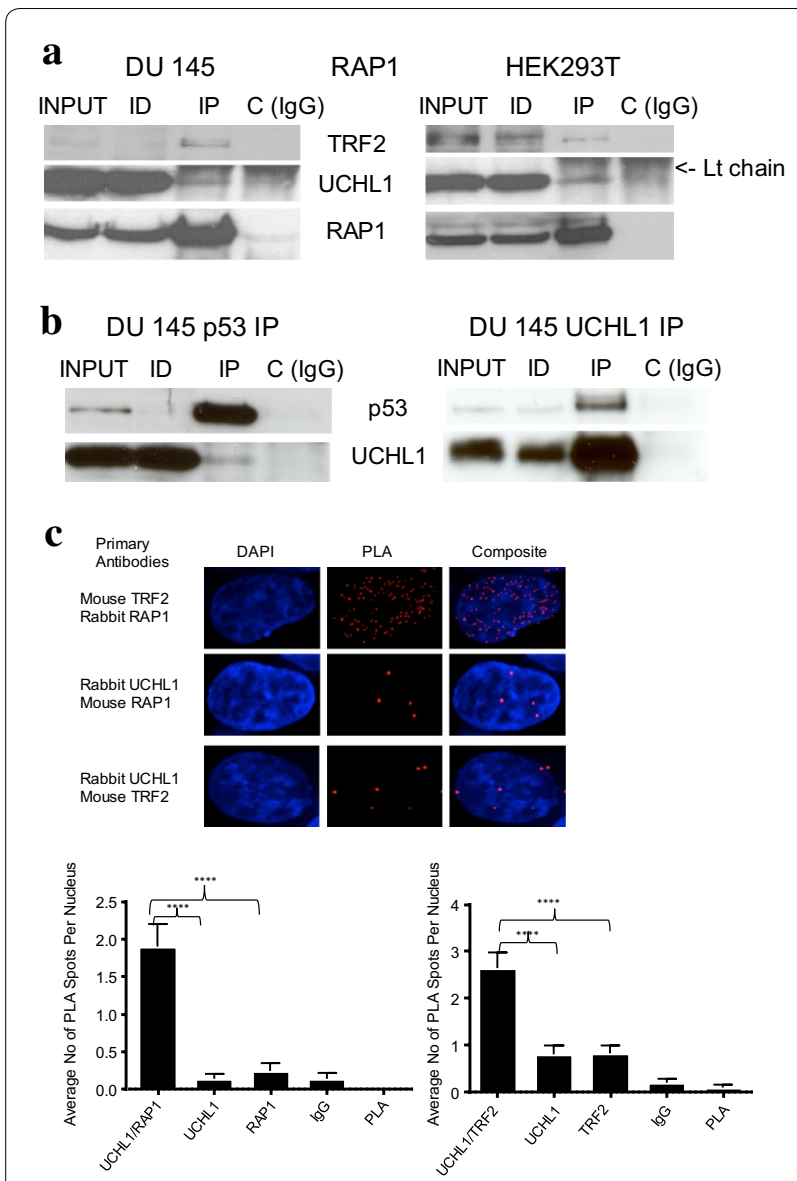

Fig. 5 UCHL1 interacts with the shelterin complex and the nuclear scaffold. a DU 145 or HEK293T cellular lysates in a low stringency buffer were incubated with anti-TRF2 antibodies or control lgG. The immunoprecipitate (IP), and equal volumes of lysate (Input) and immunodepleted (ID) fractions were analyzed by immunoblotting with the indicated antibodies. b In left panel, DU 145 cellular lysate in a low stringency buffer was incubated with anti-p53 antibodies or control lgG. In right panel, cell lysate in a high stringency buffer of DU 145 cells treated with the cross-linker DSP was incubated with anti-UCHL1 antibodies or control lgG. The immunoblot analysis was done as in (a). c In situ PLA images of the interaction between TRF2 and RAP1 (positive control), UCHL1 and RAP1 or UCHL1 and TRF2 in HEK293T cells. PLA signals appear as discrete red dots and nuclei are visualized by DAPI (blue). A total of 30 nuclei per group were quantified. The average number of PLA foci per nucleus was graphed with error bars representing standard errors of the means. Single primary antibodies, isotype control and PLA probes only were used as negative controls as indicated. ${ }^{* * *} p<0.0001$ (determined by one-way ANOVA)

In DU 145 cells, we confirmed that p53 binds to UCHL1 (Fig. 5b).

We next applied the proximity ligation assay (PLA) to observe interactions between UCHL1 and the shelterin proteins RAP1 and TRF2 in HEK293T cells. The TRF2-RAP1 interaction was used as a positive control
[25] (Fig. 5c). Appropriate single primary antibodies, isotype control and PLA probes only were used as negative controls (Additional file 4). A total of 30 nuclei per group were quantified. Interactions were observed between UCHL1 and RAP1 and between UCHL1 and TRF2. However, the number of interactions was considerably less than that observed between RAP1 and TRF2 (Fig. 5c).

Double immunofluorescence experiments with antibodies against UCHL1 and TRF2 were done to determine whether we could observe co-localization of these two proteins in HEK293T cells. A low level of co-localization of UCHL1 and TRF2 was observed, with most UCHL1 and TRF2 having distinct locations (Fig. 6a). In immuno-FISH studies, we determined the co-association of UCHL1 or TRF2 with the telomere. For both proteins, there was a low level of association with the telomere (Fig. 6).

Together, these observations are consistent with a weak or transient interaction between UCHL1 and the shelterin proteins.

\section{Mutant p53 is not associated with UCHL1-binding sites}

The (TTAGGG) $n$ repeat has the potential to form a G-quadruplex structure. Several loci that UCHL1 interacts with (chr 18 subtelomeric region, upstream promoter region of PCGF3 and intron of DDX11L2) have the potential to form G-quadruplexes in DU 145 cells [26]. TRF2, POT1 and mutant p53 are G-quadruplexbinding proteins $[27,28]$. As HEK293T and DU 145 cells express mutant p53 [29], it was conceivable that mutant p53 was recruiting UCHL1 to the ITS and telomeres. We performed p53 ChIP assays with dual crossed-linked PC-3, HEK293T and DU 145 cells. The PC-3 cells do not express p53 and thus served as a negative control in the ChIP assays (Additional file 5a). We did not observe an association with the five UCHL1 binding sites tested (Additional file 5b). We conclude that mutant p53 is not involved in recruiting UCHL1 to the ITS.

\section{UCHL1 and RAP1 are associated with the nuclear scaffold}

The nuclear scaffold, also referred to as nuclear matrix, is formed by a network of protein-RNA interactions. It has a central role in organization of the chromatin structure [30] and provides a platform for nuclear processing such as transcription, replication and RNA processing [31-39]. It had been reported that TIN2 was associated with the nuclear scaffold in normal human fibroblasts [40]. We initially observed that UCHL1 was associated with DU 145 nuclear DNA by using the cross-linker cisplatin. As cisplatin preferentially cross-links nuclear scaffold proteins to DNA [41], we determined whether UCHL1 was a nuclear scaffold associated protein. DU 145 nuclei were digested extensively with DNase I, and 


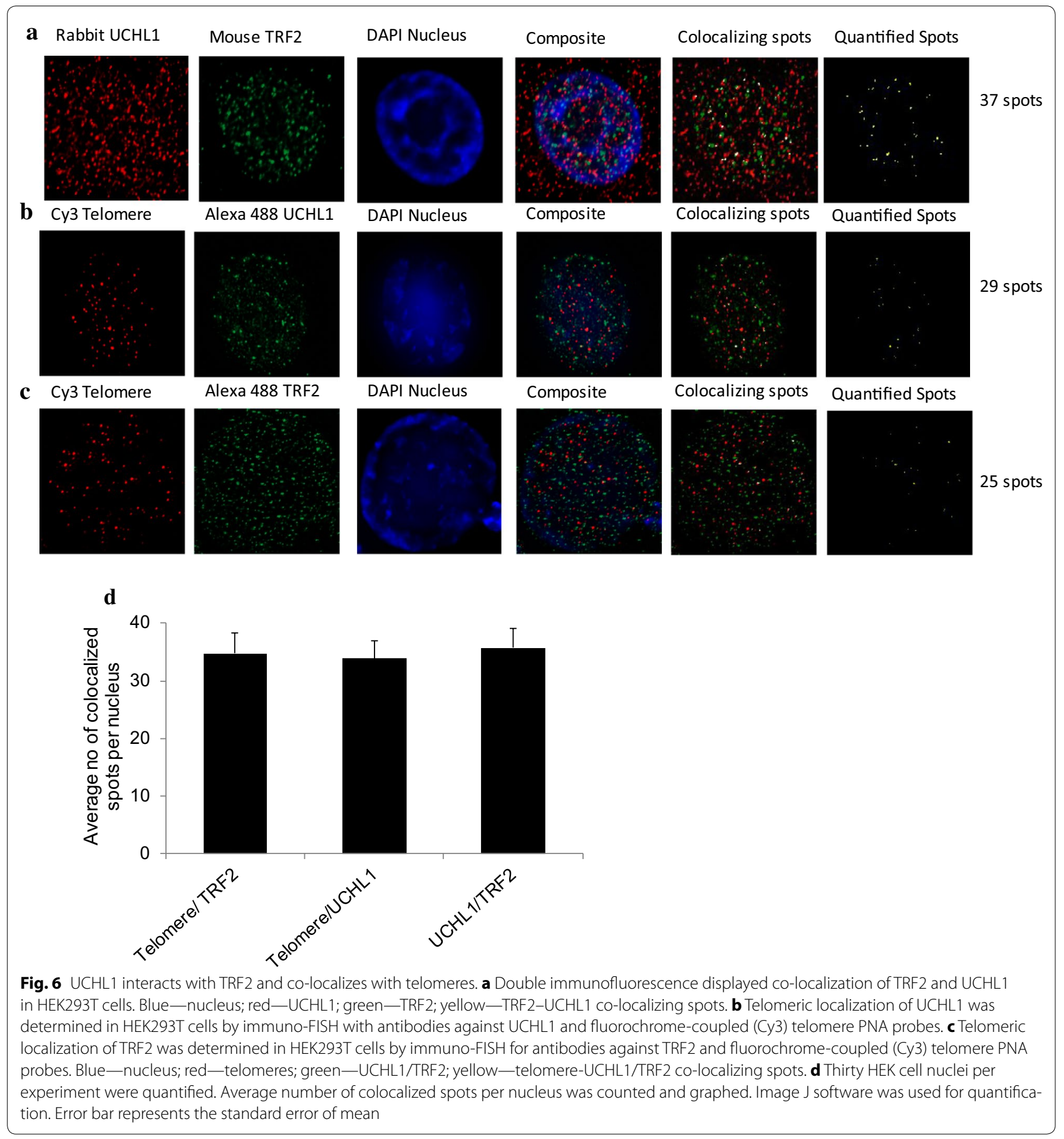

chromatin was extracted with $0.25 \mathrm{M}$ ammonium sulfate. The nuclear scaffold fraction was depleted in histones and enriched in lamins (Fig. 7a). Figure $7 \mathrm{~b}$ shows that RAP1 and, to a lesser extent, UCHL1 were associated with the nuclear scaffold of DU 145 cells. RAP1 was also associated with the nuclear scaffold of PC-3 cells (Fig. 7b). We next tested whether the protein-protein cross-linker DSP would increase the retention of
UCHL1 and TRF1 to the nuclear scaffold of DU 145 cells. With the DSP-treated cells, there was a marked increase in UCHL1 and TRF1 with the nuclear scaffold (Fig. 7b). Further, there was a decrease in the amount of RAP1 in the ammonium sulfate fraction. These observations suggest that RAP1 may have a role in recruiting the shelterin complex and UCHL1 to the nuclear scaffold. 


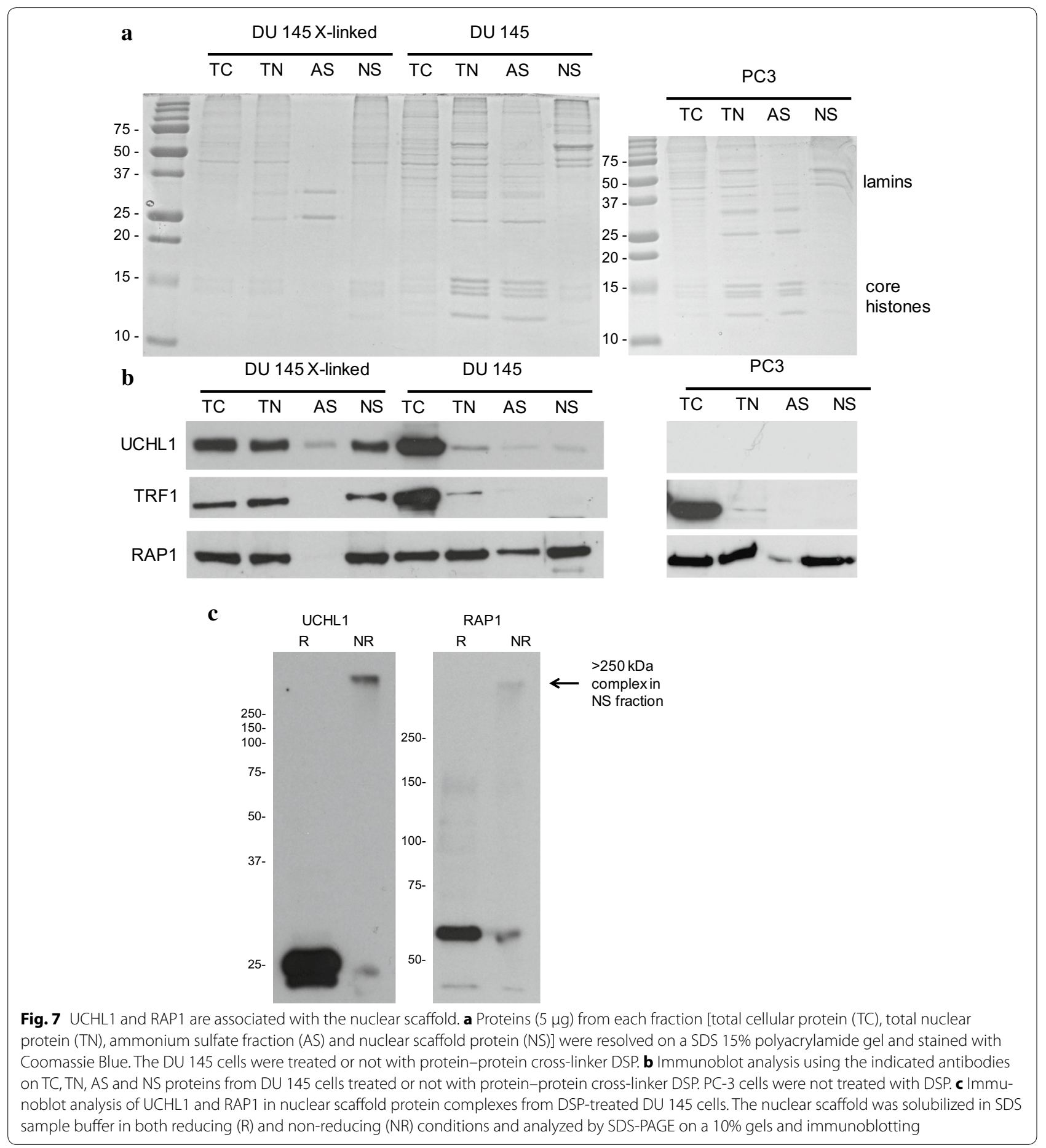

To determine whether UCHL1 was associated with the nuclear scaffold bound RAP1, DU 145 cells were crosslinked with DSP before isolating the nuclear scaffold. The nuclear scaffold was solubilized in SDS sample buffer, and the proteins as cross-linked complexes were electrophoretically resolved on a $10 \%$ polyacrylamide SDS gel and analyzed by immunoblotting with anti-UCHL1 antibodies. In non-reducing conditions, the UCHL1 and RAP1 barely resolved in the gel and were in a very large complex with a molecular mass in excess of $250 \mathrm{kDa}$ (Fig. 7c). In reducing conditions which break the cross-links, UCHL1 and RAP1 were observed. To determine whether 
UCHL1 and RAP1 were associated in the large complex, we attempted co-immunoprecipitation experiments in which UCHL1 was immunoprecipitated from the solubilized nuclear scaffold protein fraction from DSP crosslinked DU145 cells. Unfortunately, we could not generate a conclusive result since UCHL1 and RAP1 both electrophoresed at the same position as the light and heavy IgG chains (Additional file 6). However, we did not observe either a UCHL1 or RAP1 band in the immunodepleted (ID) fraction, suggesting that both UCHL1 and RAP1 were together in the large protein complex.

\section{Knockdown of UCHL1 does not alter RAP1 and TRF2 levels} As UCHL1 protects proteins (NOXA, p53, HIF-1-alpha, EGFR) from turnover by removing polyubiquitin chains [6-10], it was possible that UCHL1 had a role in regulating the turnover the shelterin proteins. To test this idea, we performed UCHL1 knockdown experiments with HEK293T cells. In the cells in which there was a reduction of 93\% in UCHL1 levels, there was a minimal effect on the levels RAP1 (6\% reduction) and TRF2 (Fig. 8). We conclude that UCHL1 does not have a role in the stabilization of RAP1.

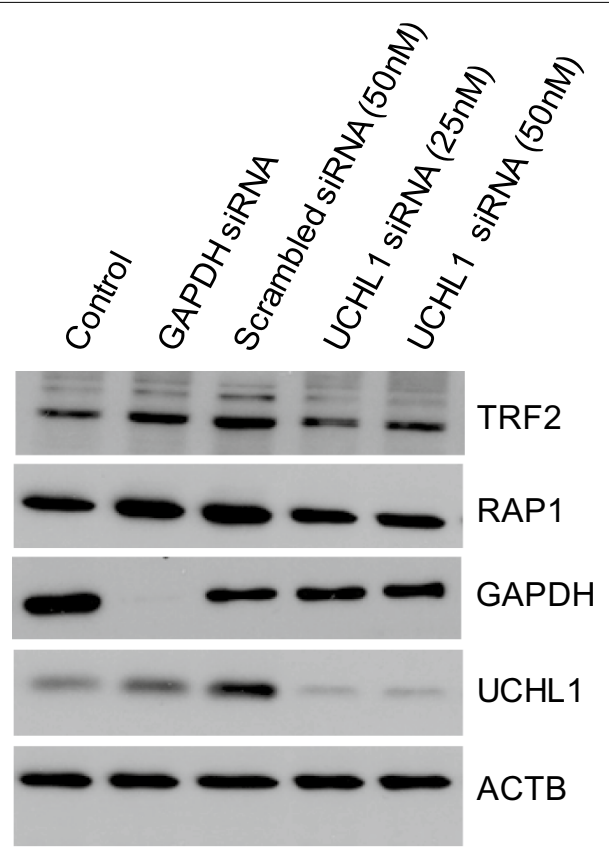

Fig. 8 UCHL1 knockdown and shelterin protein levels. HEK293T cells were transfected with GAPDH siRNA (50 nM), scrambled siRNA control $(50 \mathrm{nM})$ and two UCHL1 siRNA with the final concentrations of 25 and $50 \mathrm{nM}$. Whole protein lysates were extracted from control and siRNA-transfected HEK293T cells $72 \mathrm{~h}$ posttransfection, and immunoblot analysis was performed with antibodies against UCHL1, RAP1, TRF2 and GAPDH. Beta actin was used as an internal control

\section{Discussion}

UCHL1 has multiple roles in ubiquitin homeostasis, protein stability and tumor progression. In this study, we discovered a new role for UCHL1 in associating with nuclear DNA. In addition to UCHL1-expressing prostate cancer cells and HEK293T cells, we are in the process of characterizing other cell types including lung cancer and medulloblastoma cell lines. We are finding that when UCHL1 is expressed, the protein is associated with DNA (unpublished data).

Cisplatin or formaldehyde cross-linking in combination with hydroxyapatite chromatography has been a productive approach to discover proteins that are differentially associated with nuclear DNA in cells. Our finding that KSRP/FUBP2 was cross-linked to DNA in prostate cancer cell lines supports the validity of our approach as KSRP is a known single-stranded DNA-binding protein upregulated in some cancers [42, 43]. Previously, we used this method to demonstrate that peroxiredoxin 1 (PRDX1) was associated with the nuclear DNA in triple negative breast cancer cells [17]. As with PRDX1, UCHL1 binds DNA indirectly through interaction with a DNAbinding protein, which for UCHL1 includes the shelterin complex. UCHL1 and the shelterin complex bind at telomeres and interstitial TTAGGG repeats located throughout the mammalian cell genome. There is mounting evidence that ITS plays a role in genomic instability and in human disease [44-47].

Although tandem (TTAGGG) $n$ repeats are found primarily at telomeres, approximately $40 \%$ of the (TTAGGG) $n$ sequences locate to pericentric and ITSs [48]. There are three classes of ITSs in the human genome (short, long subtelomeric and fusion) [49]. The short ITSs are found at over 50 loci in the human chromosome. In contrast to telomeres which stabilize chromosomes, ITSs destabilize chromosomes [50] and some ITSs coexist with fragile sites [49]. Site-specific insertion of a 800-bp (TTAGGG) $n$ sequence into the intron of the Chinese hamster APRT gene resulted in a 30-fold increase in gene rearrangements with the (TTAGGG) $n$ repeat [50]. UCHL1 is located with ITSs in the regions 2q31 and 21q22, which demonstrate instability, and at ITSs in 2q14 which is an aphidicolin-inducible common fragile site [51, 52].

The insertion of the (TTAGGG) $n$ repeat into the intron did not affect the expression of the APRT gene. In DU 145 prostate cancer cells, UCHL1 was frequently found at ITSs located in the intron of genes that were either expressed or silent. Several reports show that TRF2 regulates gene expression through binding to ITSs located within the upstream promoter region or in introns, and UCHL1 may modify this TRF2 activity $[22,53]$. 
It is possible that UCHL1 has a role in regulating gene expression through changes in the stabilization of shelterin proteins. As several shelterin proteins (TRF1, TRF2, POT1 and RAP1) are ubiquitinated, UCHL1 may have a role in regulating the stability of these proteins. However, our studies do not provide support for such a function. UCHL1 may regulate the nuclear location of shelterin-associated genomic regions by regulating the association of DNA sequences with the nuclear scaffold. It had been reported that TIN2 is bound to the nuclear scaffold [40]. We show here that RAP1 is associated with the nuclear scaffold in DU 145 cells and PC-3 cells, which lack UCHL1 expression. This observation suggests that RAP1 is key in recruiting the shelterin complex to the nuclear scaffold along with the shelterinbound ITS. Whether UCHL1 has a role in modulating the interaction between shelterin-bound telomere/ITS, lamins and the nuclear scaffold remains to be determined $[54,55]$.

\section{Conclusions}

Deregulated expression and mutations in UCHL1 are associated with human diseases including cancer, Parkinson's disease, Alzheimer disease and type 2 diabetes [5661]. The newly discovered ability of UCHL1 to associate with components of the shelterin complex and telomeric/ ITSs may be relevant in these disease processes.

\section{Methods}

\section{Cell culture}

BPH-1, LNCaP, PC-3, DU 145 and HEK293T cell lines were obtained from the American Type Culture Collection. PC-3M, PC-3M LN4 and PC-3M Pro cells were obtained from Dr. Sui Huang and C4-2 cells from Dr. Paul Rennie. BPH-1, LNCaP, PC-3, PC-3 derived and C4-2 cells were grown in RPMI-1640 medium (Life Technologies). DU 145 cells were grown in EMEM medium (Life Technologies) and HEK293T cells in DMEM medium (Life Technologies). All the media were supplemented with 10\% FBS and 1\% antibiotic-antimycotic (Life Technologies). The cells were grown at $37{ }^{\circ} \mathrm{C}$ with $5 \% \mathrm{CO}_{2}$. DU 145 and HEK293T cell lines were authenticated by STR DNA profiling analysis [62].

\section{Isolation and analysis of proteins cross-linked to DNA}

Cells were incubated with $1 \mathrm{mM}$ cisplatin at $37{ }^{\circ} \mathrm{C}$ for $2 \mathrm{~h}$ or with $1 \%$ formaldehyde at room temperature for $10 \mathrm{~min}$, and proteins cross-linked to DNA in situ were isolated and resolved by two-dimensional gel electrophoresis. The methods to isolate and identify proteins differentially associated with DNA were described previously [17].
DSP cross-linking of proteins, immunoprecipitation (IP) and immunoblotting

These procedures were performed as described [63]. To cross-link proteins, cells were incubated with $1 \mathrm{mM}$ DSP (dithiobis[succinimidylpropionate]) (Thermo Fisher Scientific) at room temperature for $30 \mathrm{~min}$. Antibodies against UCHL1 (R\&D Systems, Inc.), Lamin A/C (Upstate Biotechnology), HDAC1 (Millipore), actin (Sigma-Aldrich), GAPDH (Santa Cruz Biotechnology), p53 (Abcam), TRF1 (Novus Biologicals), TRF2 (Novus Biologicals), RAP1 (TERF2IP) (Bethyl Laboratories) and KSRP (a gift from Dr. Douglas L. Black) were used.

\section{ChIP and ChIP-seq assays}

ChIP experiments were done as previously described [64] with the following modifications. In one protocol, DU 145 cells were treated with $1 \%$ formaldehyde for $10 \mathrm{~min}$ at room temperature and chromatin was submitted to sonication to generate fragments of an average length of 200-300 bp. In a second protocol, DU 145 and HEK293T cells were incubated with $1 \mathrm{mM}$ DSP for $30 \mathrm{~min}$ at room temperature and then with $0.5 \%$ formaldehyde for $10 \mathrm{~min}$. Dual cross-linked chromatin was processed to mononucleosomes (> 60\% mononucleosomes) by micrococcal nuclease (Worthington Biochemical Corporation). The mouse monoclonal anti-UCHL1 antibody (R\&D Systems) was used to immunoprecipitated chromatin fragments. Primers used to amplify ChIPped DNA were as follows: CLIC6 forward, 5'-CTAACCCTAACCGTAACTCTAAC- $3^{\prime}$, and reverse, 5'-CTCCCAAGCACCTTGTC-3'; RASGRF1 forward, 5'-ССТТСССТАТССТСССТТАТ- $3^{\prime}$, and reverse, 5'-CAAGTTCCCTTCTCACTCTG-3'; Chr10p15 forward, $5^{\prime}$-CCACTGCTGAGTTACAGGCA-3' ${ }^{\prime}$, and reverse, 5'-CCCTGGTCAAAATGTCATCC-3'; HS3ST4 forward, 5'-GTGCGTCTATGAGGGCTGCCA- ${ }^{\prime}$, and reverse, 5'-AGGCACCCAGTGGCTTTAACAGT-3'; CFDP1 forward, 5'-TTGCCAGCCCCACCCACTCT-3' ${ }^{\prime}$, and reverse, 5'-TCCCGGTCCTTTTTACCCGTCTGT-3'. Enrichment values are the mean of three independent experiments. Error bars indicate standard error.

\section{ChIP DNA preparation for SOLiD ChIP-sequencing}

The ChIP and input DNA for ChIP-seq were purified by magnetic AgencourtAMPure XP beads (Beckman Coulter) as per manufacturer's instructions. The DNA was quantified by the Qubit 2.0 Fluorometer (Life Technologies). The subsequent ChIP-seq library preparation steps were performed according to the 5500 SOLiD fragment library protocol (Life technologies). The ChIP and input DNA size was first analyzed by the high-sensitivity DNA kit and 2100 Bioanalyzer (Agilent Technologies). Approximately $20 \mathrm{ng}$ of ChIP DNA was end-repaired and 
size-selected (100-250 bp). This was followed by dA tailing and ligation of SOLiD barcodes. Finally, DNA libraries were prepared by ePCR and loaded onto the flowchip for sequencing by the SOLiD platform.

\section{SOLiD sequence mapping}

A total of 181,900,271 and 70,075,439 50-base SOLiD UCHL1 ChIP-seq sequence reads were generated from four DU 145 and two HEK293T cell samples, respectively. We also analyzed three samples of 19,524,349 sequence reads of the SOLiD ChIP-seq data from NCBI GEO (GSE26005). All these sequences were ensured by quality check (noise to signal ratio and bamStats after mapping). The sequence reads were mapped on the human reference genome (hg19) using Lifescope v2.5.1 software (Life Technologies) with 2-mismatch settings. The GSE26005 sequences were mapped using Bowtie version 2 [65].

\section{Peak calling and annotation}

The binding site candidates were identified by comparing ChIP sample to input sample using the model-based analysis of ChIP-seq (MACS) peak caller [66] with a $p$ value $1 \mathrm{e}-5$ and an mfold cutoff of high limit of 30 and low limit of 10. We used the software CEAS [67] to analyze the peak distribution among the genome and their location regarding to genes. We used the Ensembl 75 for gene annotations. We searched the binding site sequences against the TRANSFAC Professional v9.3 database (http://www.biobase.de) by Match program with minimal false discovery rate of 0.1 cutoff. The common peaks among different samples were analyzed by custom script. We determined that two peaks overlapped if one peak's center fell into another peak's range.

\section{Data viewing}

Browser views of gene tracks, ChIP-seq data and peaks are shown using Integrated Genomics Viewer (IGV) after data normalization using igvtools [68] or Partek Genomics Suite v6.6.

\section{Motif analysis}

The sequences of the 191 peaks were extracted from the human genome hg19 reference using the peak bed file and bedtools. The motifs among these sequences were analyzed by MEME discovery tools [69] with W:5-25 settings.

\section{GO term analysis}

The 76 genes corresponding to 191 UCHL1 peaks were obtained using software HOMER [70]. Further, these 76 genes were subjected to $\mathrm{GO}$ analysis using software DAVID [71].

\section{Double immunofluorescence}

HEK293T cells were seeded and cultured overnight on 3-aminopropyl triethoxysilane (APTES, Sigma) coated glass slides. The cells were fixed for $20 \mathrm{~min}$ in $3.7 \%$ formaldehyde (Fisher Scientific), permeabilized using 0.25\% Triton X-100 and blocked with $4 \times$ SSC/4\%BSA for $1 \mathrm{~h}$ at room temperature. Rabbit antibodies against PGP9.5 (UCHL1) (Abcam) and mouse antibodies against TRF2 (Novus Biologicals) were incubated for $1 \mathrm{~h}$ and then for $1 \mathrm{~h}$ again at room temperature with secondary antibodies Alexa Fluor (AF) 488 conjugated goat anti-rabbit IgG and AF594 conjugated goat anti-mouse IgG, respectively (both Life technologies). Slides were then counterstained with DAPI (Sigma), mounted with Fluoromount G (Southern Biotech) and imaged with a Zeiss Z1 microscope using a 63x oil immersion objective with NA of 1.4 and image J software.

\section{Immuno-FISH}

HEK293T cells were grown overnight on APTES-coated glass slides, fixed with $3.7 \%$ formaldehyde in PBS for 20 min at RT and permeabilized with $0.25 \%$ Triton X-100 for $10 \mathrm{~min}$ at room temperature. After blocking for $1 \mathrm{~h}$ with $4 \% \mathrm{BSA}$ in $4 \mathrm{x}$ SSC buffer, slides were incubated for $1 \mathrm{~h}$ at room temperature with primary antibodies to UCHL1 (rabbit monoclonal, Abcam) and TRF2 (mouse monoclonal, Novus Biologicals). After washing, pepsin (Sigma) digestion was done for $4 \mathrm{~min}$ at $37^{\circ} \mathrm{C}$. Cells were postfixed in 3.7\% formaldehyde for $2 \mathrm{~min}$ at room temperature and submitted to dehydration through ethanol series. Fluorochrome-coupled (Cy3) Telomere PNA probe (DAKO) was applied ( $5 \mu \mathrm{l}$ probe/slide), and following denaturation at $80^{\circ} \mathrm{C}$ for $3 \mathrm{~min}$, hybridization was done for $2 \mathrm{~h}$ at $30^{\circ} \mathrm{C}$. Slides were washed in $70 \%$ deionized formamide (Sigma) in $10 \mathrm{mM}$ Tris pH 7.4, $2 \times$ SSC $\left(5 \mathrm{~min}\right.$ at $\left.55^{\circ} \mathrm{C}\right), 0.1 \times \mathrm{SSC}$ and $2 \times \mathrm{SSC} / 0.05 \%$ Tween-20 at room temperature. Secondary antibody AF488 goat anti-rabbit IgG or AF488 goat anti-mouse IgG was applied to the slides and incubated for $1 \mathrm{~h}$ at RT. Slides were washed in $2 \times \mathrm{SSC} / 0.05 \%$ Tween 20, counterstained with DAPI (Sigma), mounted with Fluoromount G (Southern Biotech) and imaged with a Zeiss Z1 microscope using a $63 \times$ oil immersion objective with NA of 1.4 and Zen Software (Zeiss).

\section{Proximity ligation assay}

PLA experiments were done on HEK293T cells, using the Duolink kit (Sigma-Aldrich) as previously described [25]. Antibodies used were anti-UCHL1 rabbit monoclonal (Abcam), anti-TRF2 mouse monoclonal (Novus Biologicals), anti-RAP1 (TERF2IP) mouse monoclonal (Abcam), anti-RAP1 (TERF2IP) rabbit polyclonal (Bethyl Laboratories), rabbit IgG and mouse IgG (Sigma-Aldrich). 


\section{Nuclear scaffold protein isolation} and immunoprecipitation

Nuclear scaffold proteins were isolated from DU 145 cells as described previously [72]. Cross-linking was performed at room temperature for 30 min with $1 \mathrm{mM}$ DSP (dithiobis[succinimidylpropionate]) (Thermo Fisher Scientific). Then, cells submitted or not to cross-linking were resuspended in TNM buffer $(100 \mathrm{mM} \mathrm{NaCl}$, $300 \mathrm{mM}$ sucrose, $10 \mathrm{mM}$ Tris- $\mathrm{HCl}, \mathrm{pH}$ 7.4, $2 \mathrm{mM} \mathrm{MgCl}$ and $1 \%$ thiodiglycol $\mathrm{v} / \mathrm{v}$ ) containing $1 \mathrm{mM}$ PMSF, $30 \mathrm{mM}$ sodium butyrate and phosphatase inhibitors. Triton $\mathrm{X}-100$ was added to a final concentration of $0.25 \%(\mathrm{v} / \mathrm{v})$. An aliquot of this supernatant was saved as the total cellular protein fraction. Nuclei $\left(20 \mathrm{~A}_{260} / \mathrm{ml}\right)$ were digested with $100 \mu \mathrm{g} / \mathrm{ml}$ DNase 1 (Sigma-Aldrich) for $1 \mathrm{~h}$ at room temperature in DIG buffer $(50 \mathrm{mM} \mathrm{NaCl}, 300 \mathrm{mM}$ sucrose, $10 \mathrm{mM}$ Tris-Cl, $\mathrm{pH} 7.4,3 \mathrm{mM} \mathrm{MgCl} 2,1 \%$ (v/v) thiodiglycol, and $0.5 \%(\mathrm{v} / \mathrm{v})$ Triton $\mathrm{X}-100)$ with $1 \mathrm{mM}$ PMSF, $30 \mathrm{mM}$ sodium butyrate and phosphatase inhibitors. An aliquot was saved as the total nuclear fraction. Ammonium sulfate was added slowly to a final concentration of $0.25 \mathrm{M}$ to facilitate the removal of chromatin. The sample was then centrifuged at $9600 \mathrm{~g}$ for $10 \mathrm{~min}$ at $4{ }^{\circ} \mathrm{C}$, and the supernatant, termed the ammonium sulfate fraction, was dialyzed against water and saved. The pellet containing the nuclear scaffold was resuspended in $8 \mathrm{M}$ urea. The protein concentration in the four fractions was quantified according to the manufacturer's instructions using the Pierce BCA Protein Assay kit (Thermo Fisher Scientific). SDS sample loading buffer with or without reducing agent $\beta$-mercaptoethanol was added to nuclear scaffold protein fraction. Samples were boiled and analyzed by SDS-PAGE and immunoblotting.

For immunoprecipitation analyses, the nuclear scaffold pellet was resuspended in RIPA buffer $(10 \mathrm{mM}$ Tris-HCl $\mathrm{pH}$ 8.0, 1\% Triton X-100, 0.1\% SDS, 0.1\% SDC) and sonication was done to fully resuspend the proteins. AntiUCHL1 antibody (R\&D Systems) and control mouse IgG (Millipore) were used, and then, magnetic Dynabeads protein G (Thermo Fisher Scientific) was added. Reducing sample buffer was added to both the IP and IgG beads as well as the input and immunodepleted (ID) fractions that were saved at equal volumes. This was followed by boiling, separation of magnetic beads by a magnet, loading the precipitate in sample buffer on a $12 \%$ polyacrylamide gel, SDS-PAGE and immunoblotting.

\section{UCHL1 knockdown by siRNA transfection}

HEK293T cells were transiently transfected with UCHL1 specific ON-TARGET plus siRNA-SMART pool (GE Dharmacon Fisher Scientific). ON-TARGET plus Human GAPDH siRNA was used as positive control and scrambled siRNA as negative control. Transfection was performed using DharmaFECT transfection reagent 1 following the manufacturer's protocol. Whole cell lysate was isolated after $72 \mathrm{~h}$ posttransfection. Immunoblot analysis was performed with the cell lysates with antibodies against UCHL1, RAP1, TRF2 and GAPDH. $\beta$-Actin was used as an internal control.

To calculate the knockdown efficiency of UCHL1 siRNA, we performed immunoblot analyses with increasing amounts $(0.5-10 \mu \mathrm{g})$ of lysate of control and UCHL1 siRNA-transfected cells. Lysates were loaded on a $12 \%$ acrylamide gel, and immunoblot analysis was performed using UCHL1-, RAP1- and GAPDH-specific antibodies. The chemiluminescent detection was done with a ChemiDoc gel imaging system, and the protein levels were determined by protein band analysis using Image Lab analysis software (BioRad). To calculate the knockdown efficiency of the UCHL1-siRNA, the intensity of UCHL1 and RAP1 protein bands was normalized with the respective GAPDH intensity (protein for internal control) in control and siRNA-transfected samples. The percentage of remaining UCHL1 and RAP1 in the knockdown samples was calculated by comparing the normalized intensity of UCHL1 and RAP1 proteins with the control.

\section{Additional files}

Additional file 1. List of UCHL1 binding sites in DU 145 cells.

Additional file 2. List of UCHL1 binding sites within and 5-kb up or downstream genes in DU 145 cells.

Additional file 3. GO analysis using software DAVID for the 76 genes corresponding to 191 UCHL1 peaks. The percentage (\%) of the input gene count within the term group was calculated. Fold enrichment is the ratio of percentage of user's genes in a term group versus the percentage of the term genes in human genome (population background). The $p$ value was calculated by a modified Fisher's exact test (EASE score). FDR is the false discovery rate.

Additional file 4. In situ PLA images of negative controls used in PLA assays.

Additional file 5. Mutant p53 does not associate with UCHL1 binding sites. a Expression of p53 in DU 145, PC-3 and HEK293T cells. Ten micrograms of protein (whole cell lysate) was resolved by PAGE and immunoblotted with antibodies against p53 and GAPDH (internal loading control). b p53 ChIP qPCR was done for the listed UCHL1 binding sites in PC-3, DU 145 and HEK293T cells. The values are presented as fold enrichment and normalized to mock IgG ChIP and PC-3 p53 ChIP.

Additional file 6. UCHL1 may interact with RAP1 as part of a nuclear scaffold complex. Nuclear scaffold lysate from DSP-treated DU 145 cells in RIPA buffer was incubated with an anti-UCHL1 antibody or control IgG. The immunoprecipitate (IP), and equal volumes of lysate (Input) and immunodepleted (ID) fractions were analyzed by immunoblotting with UCHL1 and RAP1 antibodies. Mouse/rabbit Rockland TrueBlot secondary antibodies were used.

\section{Abbreviations}

BJ cells: BJHELTRas ${ }^{\mathrm{mc}}$ cells; ChIP: chromatin immunoprecipitation; ITS: interstitial telomeric site; PAGE: two-dimensional polyacrylamide gel electrophoresis; seq: sequencing; RAP1 (TERF2IP): telomeric repeat binding factor 2-interacting 
protein $1 ;$ TRF1/2: telomeric repeat binding factor 1/2; UCHL1: ubiquitin C-terminal hydrolase isozyme L1.

\section{Authors' contributions}

Al carried out the ChIP and ChIP-seq assays as well as the IPs and IBs, participated in data interpretation and prepared figures. SL performed the initial experiments identifying UCHL1 as a candidate for further study. VB analyzed the proteins bound to the nuclear scaffold. FB and TK performed the PLA, double immunofluorescence and co-immuno-FISH. TK also reviewed the manuscript. WX performed the bioinformatics analyses, with the assistance of PA. JRD conceived of the study, participated in its design and coordination and reviewed the manuscript. All authors read and approved the final manuscript.

\section{Author details}

${ }^{1}$ Children's Hospital Research Institute of Manitoba, University of Manitoba, 715 McDermot Avenue, Room 600A, Winnipeg, MB R3E 3P4, Canada. ${ }^{2}$ Department of Human Anatomy and Cell Science, University of Manitoba, 130-745 Bannatyne Ave, Winnipeg, MB R3E 0J9, Canada.

\section{Acknowledgements}

We thank Geneviève Delcuve for helping with the manuscript preparation, Carolina Gonzalez for library preparation, Nianguang Cai for motif analysis, as well as Dr Sui Huang for the PC-3 cell line series and Dr. Douglas L. Black for the antibody against KSRP. We also thank Dr Eric Gilson's group for providing us with some of the primer sequences for ChIP-seq qPCR validation analyses.

\section{Competing interests}

The authors declare that they have no competing interests.

\section{Availability of supporting data}

The sequencing data are available from GEO under accession number GSE97111. The reviewer access link is: https://www.ncbi.nlm.nih.gov/geo/ query/acc.cgi?token=ajodakqclxufvif\&acc=GSE97111.

\section{Consent for publication}

All authors have read and approved the manuscript.

\section{Ethical approval and consent to participate}

Not applicable.

\section{Funding}

This work was supported by the Cancer Research Society and CancerCare Manitoba Foundation (JRD \& WX) and Natural Sciences and Engineering Council of Canada (NSERC), Canadian Institutes of Health Research (CIHR), and Canadian Breast Cancer Foundation (CBCF) (TK).

\section{Publisher's Note}

Springer Nature remains neutral with regard to jurisdictional claims in published maps and institutional affiliations.

Received: 9 April 2017 Accepted: 31 October 2017

Published online: 10 November 2017

\section{References}

1. Day IN, Thompson RJ. UCHL1 (PGP 9.5): neuronal biomarker and ubiquitin system protein. Prog Neurobiol. 2010;90:327-62.

2. Pfoh R, Lacdao IK, Saridakis V. Deubiquitinases and the new therapeutic opportunities offered to cancer. Endocr Relat Cancer. 2015;22:T35-54.

3. Wilkinson KD, Lee KM, Deshpande S, Duerksen-Hughes P, Boss JM, Pohl J. The neuron-specific protein PGP 9.5 is a ubiquitin carboxyl-terminal hydrolase. Science. 1989;246:670-3.

4. Larsen CN, Krantz BA, Wilkinson KD. Substrate specificity of deubiquitinating enzymes: ubiquitin C-terminal hydrolases. Biochemistry. 1998;37:3358-68.

5. Das C, Hoang QQ, Kreinbring CA, Luchansky SJ, Meray RK, Ray SS, et al. Structural basis for conformational plasticity of the Parkinson's disease-associated ubiquitin hydrolase UCH-L1. Proc Natl Acad Sci USA. 2006;103:4675-80.

6. Brinkmann K, Zigrino P, Witt A, Schell M, Ackermann L, Broxtermann P, et al. Ubiquitin C-terminal hydrolase-L1 potentiates cancer chemosensitivity by stabilizing NOXA. Cell Rep. 2013;3:881-91.

7. Goto Y, Zeng L, Yeom CJ, Zhu Y, Morinibu A, Shinomiya K, et al. UCHL1 provides diagnostic and antimetastatic strategies due to its deubiquitinating effect on HIF-1alpha. Nat Commun. 2015;6:6153.

8. Jin Y, Zhang W, Xu J, Wang H, Zhang Z, Chu C, et al. UCH-L1 involved in regulating the degradation of EGFR and promoting malignant properties in drug-resistant breast cancer. Int J Clin Exp Pathol. 2015;8:12500-8.

9. Li L, Tao Q, Jin H, van Hasselt A, Poon FF, Wang X, et al. The tumor suppressor UCHL1 forms a complex with p53/MDM2/ARF to promote p53 signaling and is frequently silenced in nasopharyngeal carcinoma. Clin Cancer Res. 2010;16:2949-58.

10. Liu Y, Fallon L, Lashuel HA, Liu Z, Lansbury PT Jr. The UCH-L1 gene encodes two opposing enzymatic activities that affect alpha-synuclein degradation and Parkinson's disease susceptibility. Cell. 2002;111:209-18.

11. Hsu SH, Lai MC, ErTK, Yang SN, Hung CH, Tsai HH, et al. Ubiquitin carboxyl-terminal hydrolase L1 (UCHL1) regulates the level of SMN expression through ubiquitination in primary spinal muscular atrophy fibroblasts. Clin Chim Acta. 2010:411:1920-8.

12. Osaka H, Wang YL, Takada K, Takizawa S, Setsuie R, Li H, et al. Ubiquitin carboxy-terminal hydrolase L1 binds to and stabilizes monoubiquitin in neuron. Hum Mol Genet. 2003;12:1945-58.

13. Hurst-Kennedy J, Chin LS, Li L. Ubiquitin C-terminal hydrolase 11 in tumorigenesis. Biochem Res Int. 2012;2012:123706.

14. Leiblich A, Cross SS, Catto JW, Pesce G, Hamdy FC, Rehman I. Human prostate cancer cells express neuroendocrine cell markers PGP 9.5 and chromogranin A. Prostate. 2007;67:1761-9.

15. Jang MJ, Baek SH, Kim JH. UCH-L1 promotes cancer metastasis in prostate cancer cells through EMT induction. Cancer Lett. 2011;302:128-35.

16. Bheda A, Shackelford J, Pagano JS. Expression and functional studies of ubiquitin C-terminal hydrolase L1 regulated genes. PLoS ONE. 2009;: :e6764.

17. Wang X, He S, Sun JM, Delcuve GP, Davie JR. Selective association of peroxiredoxin 1 with genomic DNA and COX-2 upstream promoter elements in estrogen receptor negative breast cancer cells. Mol Biol Cell. 2010;21:2987-95.

18. Thalmann GN, Anezinis PE, Chang SM, Zhau HE, Kim EE, Hopwood VL, et al. Androgen-independent cancer progression and bone metastasis in the LNCaP model of human prostate cancer. Cancer Res. 1994;54:2577-81.

19. Pettaway CA, Pathak S, Greene G, Ramirez E, Wilson MR, Killion JJ, et al. Selection of highly metastatic variants of different human prostatic carcinomas using orthotopic implantation in nude mice. Clin Cancer Res. 1996;2:1627-36.

20. Shaw G, Morse S, Ararat M, Graham FL. Preferential transformation of human neuronal cells by human adenoviruses and the origin of HEK 293 cells. FASEB J. 2002;16:869-71.

21. Simonet T, Zaragosi LE, Philippe C, Lebrigand K, Schouteden C, Augereau $A$, et al. The human TTAGGG repeat factors 1 and 2 bind to a subset of interstitial telomeric sequences and satellite repeats. Cell Res. 2011;21:1028-38

22. Biroccio A, Cherfils-Vicini J, Augereau A, Pinte S, Bauwens S, Ye J, et al. TRF2 inhibits a cell-extrinsic pathway through which natural killer cells eliminate cancer cells. Nat Cell Biol. 2013;15:818-28.

23. Lee $\mathrm{OH}$, Kim H, He Q, Baek HJ, Yang D, Chen LY, et al. Genomewide YFP fluorescence complementation screen identifies new regulators for telomere signaling in human cells. Mol Cell Proteomics. 2011;10(M110):001628.

24. Yu J, Tao Q, Cheung KF, Jin H, Poon FF, Wang X, et al. Epigenetic identification of ubiquitin carboxyl-terminal hydrolase $\mathrm{L} 1$ as a functional tumor suppressor and biomarker for hepatocellular carcinoma and other digestive tumors. Hepatology. 2008;48:508-18.

25. Natarajan S, Begum F, Gim J, Wark L, Henderson D, Davie JR, et al. High Mobility Group A2 protects cancer cells against telomere dysfunction. Oncotarget. 2016;7:12761-82.

26. Lam EY, Beraldi D, Tannahill D, Balasubramanian S. G-quadruplex structures are stable and detectable in human genomic DNA. Nat Commun. 2013:4:1796 
27. Brazda V, Haronikova L, Liao JC, Fojta M. DNA and RNA quadruplex-binding proteins. Int J Mol Sci. 2014;15:17493-517.

28. Quante T, Otto B, Brazdova M, Kejnovska I, Deppert W, Tolstonog GV. Mutant p53 is a transcriptional co-factor that binds to G-rich regulatory regions of active genes and generates transcriptional plasticity. Cell Cycle. 2012;11:3290-303.

29. Leroy B, Girard L, Hollestelle A, Minna JD, Gazdar AF, Soussi T. Analysis of TP53 mutation status in human cancer cell lines: a reassessment. Hum Mutat. 2014;35:756-65.

30. Dobson JR, Hong D, Barutcu AR, Wu H, Imbalzano AN, Lian JB, et al. Identifying nuclear matrix-attached DNA across the genome. J Cell Physiol. 2017:232:1295-305

31. Davie JR. The nuclear matrix and the regulation of chromatin organization and function. Int Rev Cytol. 1995;162A:191-250.

32. Hall LL, Carone DM, Gomez AV, Kolpa HJ, Byron M, Mehta N, et al. Stable COT-1 repeat RNA is abundant and is associated with euchromatic interphase chromosomes. Cell. 2014;156:907-19.

33. Hall LL, Lawrence JB. RNA as a fundamental component of interphase chromosomes: could repeats prove key? Curr Opin Genet Dev. 2016:37:137-47.

34. Hendzel MJ, Boisvert F, Bazett-Jones DP. Direct visualization of a protein nuclear architecture. Mol Biol Cell. 1999:10:2051-62.

35. Hozak P, Hassan AB, Jackson DA, Cook PR. Visualization of replication factories attached to nucleoskeleton. Cell. 1993;73:361-73.

36. Jackson DA, Cook PR. Visualization of a filamentous nucleoskeleton with a $23 \mathrm{~nm}$ axial repeat. EMBO J. 1988;7:3667-77.

37. Jackson DA, Dickinson P, Cook PR. Attachment of DNA to the nucleoskeleton of HeLa cells examined using physiological conditions. Nucleic Acids Res. 1990;18:4385-93.

38. Fiorito E, Sharma Y, Gilfillan S, Wang S, Singh SK, Satheesh SV, et al. CTCF modulates Estrogen Receptor function through specific chromatin and nuclear matrix interactions. Nucleic Acids Res. 2016;44:10588-602.

39. Spencer VA, Samuel SK, Davie JR. Altered profiles in nuclear matrix proteins associated with DNA in situ during progression of breast cancer cells. Cancer Res. 2001:61:1362-6.

40. Kaminker PG, Kim SH, Desprez PY, Campisi J. A novel form of the telomere-associated protein TIN2 localizes to the nuclear matrix. Cell Cycle. 2009;8:931-9.

41. Samuel SK, Spencer VA, Bajno L, Sun JM, Holth LT, Oesterreich S, et al. In situ cross-linking by cisplatin of nuclear matrix-bound transcription factors to nuclear DNA of human breast cancer cells. Cancer Res. 1998:58:3004-8.

42. Briata P, Bordo D, Puppo M, Gorlero F, Rossi M, Perrone-Bizzozero N, et al. Diverse roles of the nucleic acid-binding protein KHSRP in cell differentiation and disease. Wiley Interdiscip Rev RNA. 2016;7:227-40.

43. Wang YY, Gu XL, Wang C, Wang H, Ni QC, Zhang CH, et al. The farupstream element-binding protein 2 is correlated with proliferation and doxorubicin resistance in human breast cancer cell lines. Tumour Biol. 2016:37:9755-69.

44. Bolzan AD. Chromosomal aberrations involving telomeres and interstitial telomeric sequences. Mutagenesis. 2012;27:1-15.

45. Bolzan AD, Bianchi MS. Telomeres, interstitial telomeric repeat sequences, and chromosomal aberrations. Mutat Res. 2006:612:189-214.

46. Levy J, Receveur A, Jedraszak G, Chantot-Bastaraud S, Renaldo F, Gondry J, et al. Involvement of interstitial telomeric sequences in two new cases of mosaicism for autosomal structural rearrangements. Am J Med Genet A. 2015:167:428-33.

47. Aksenova AY, Greenwell PW, Dominska M, Shishkin AA, Kim JC, Petes TD, et al. Genome rearrangements caused by interstitial telomeric sequences in yeast. Proc Natl Acad Sci USA. 2013;110:19866-71.

48. Krutilina RI, Smirnova AN, Mudrak OS, Pleskach NM, Svetlova MP, Oei SL, et al. Protection of internal (TTAGGG)n repeats in Chinese hamster cells by telomeric protein TRF1. Oncogene. 2003;22:6690-8.

49. Lin KW, Yan J. Endings in the middle: current knowledge of interstitial telomeric sequences. Mutat Res. 2008;658:95-110.

50. Kilburn AE, Shea MJ, Sargent RG, Wilson JH. Insertion of a telomere repeat sequence into a mammalian gene causes chromosome instability. Mol Cell Biol. 2001:21:126-35.
51. Mondello C, Pirzio L, Azzalin CM, Giulotto E. Instability of interstitial telomeric sequences in the human genome. Genomics. 2000;68:111-7.

52. Bosco N, de Lange T. A TRF1-controlled common fragile site containing interstitial telomeric sequences. Chromosoma. 2012;121:465-74.

53. El Mai M, Wagner KD, Michiels JF, Ambrosetti D, Borderie A, Destree S, et al. The telomeric protein TRF2 regulates angiogenesis by binding and activating the PDGFRbeta promoter. Cell Rep. 2014;9:1047-60.

54. Wood AM, Laster K, Rice EL, Kosak ST. A beginning of the end: new insights into the functional organization of telomeres. Nucleus. 2015;6:172-8

55. Burla R, La Torre M, Saggio I. Mammalian telomeres and their partnership with lamins. Nucleus. 2016;7:187-202

56. Tramutola A, Di Domenico F, Barone E, Perluigi M, Butterfield DA. It is all about (U)biquitin: role of altered ubiquitin-proteasome system and UCHL1 in Alzheimer disease. Oxid Med Cell Longev. 2016;2016:2756068.

57. Costes S, Huang CJ, Gurlo T, Daval M, Matveyenko AV, Rizza RA, et al. betacell dysfunctional ERAD/ubiquitin/proteasome system in type 2 diabetes mediated by islet amyloid polypeptide-induced UCH-L1 deficiency. Diabetes. 2011;60:227-38.

58. Chu KY, Li H, Wada K, Johnson JD. Ubiquitin C-terminal hydrolase L1 is required for pancreatic beta cell survival and function in lipotoxic conditions. Diabetologia. 2012:55:128-40.

59. Hussain S, Bedekovics T, Chesi M, Bergsagel PL, Galardy PJ. UCHL1 is a biomarker of aggressive multiple myeloma required for disease progression. Oncotarget. 2015;6:40704-18.

60. Corsetti V, Florenzano F, Atlante A, Bobba A, Ciotti MT, Natale F, et al. $\mathrm{NH} 2$-truncated human tau induces deregulated mitophagy in neurons by aberrant recruitment of Parkin and UCHL-1: implications in Alzheimer's disease. Hum Mol Genet. 2015:24:3058-81.

61. Zhang M, Cai F, Zhang S, Zhang S, Song W. Overexpression of ubiquitin carboxyl-terminal hydrolase L1 (UCHL1) delays Alzheimer's progression in vivo. Sci Rep. 2014;4:7298

62. Reid Y, Storts D, Riss T, Minor L. Authentication of human cell lines by STR DNA profiling analysis. In: Sittampalam GS, Coussens NP, Nelson H, Arkin M, Auld D, Austin C, Bejcek B, Glicksman M, Inglese J, Iversen PW, et al. editors. Assay guidance manual. Bethesda, MD: Eli Lilly \& Company; 2004.

63. Sun JM, Chen HY, Davie JR. Differential distribution of unmodified and phosphorylated histone deacetylase 2 in chromatin. J Biol Chem. 2007;282:33227-36

64. Drobic B, Perez-Cadahia B, Yu J, Kung SK, Davie JR. Promoter chromatin remodeling of immediate-early genes is mediated through $\mathrm{H} 3$ phosphorylation at either serine 28 or 10 by the MSK1 multi-protein complex. Nucleic Acids Res. 2010;38:3196-208.

65. Langmead B, Trapnell C, Pop M, Salzberg SL. Ultrafast and memoryefficient alignment of short DNA sequences to the human genome. Genome Biol. 2009;10:R25.

66. Zhang Y, Liu T, Meyer CA, Eeckhoute J, Johnson DS, Bernstein BE, et al. Model-based analysis of ChIP-Seq (MACS). Genome Biol. 2008;9:R137.

67. Shin H, Liu T, Manrai AK, Liu XS. CEAS: cis-regulatory element annotation system. Bioinformatics. 2009;25:2605-6.

68. Robinson JT, Thorvaldsdottir H, Winckler W, Guttman M, Lander ES, Getz $G$, et al. Integrative genomics viewer. Nat Biotechnol. 2011;29:24-6.

69. Bailey TL, Boden M, Buske FA, Frith M, Grant CE, Clementi L, et al. MEME SUITE: tools for motif discovery and searching. Nucleic Acids Res. 2009:37:W202-8.

70. Heinz S, Benner C, Spann N, Bertolino E, Lin YC, Laslo P, et al. Simple combinations of lineage-determining transcription factors prime cisregulatory elements required for macrophage and B cell identities. Mol Cell. 2010;38:576-89.

71. da Huang W, Sherman BT, Lempicki RA. Systematic and integrative analysis of large gene lists using DAVID bioinformatics resources. Nat Protoc. 2009:4:44-57.

72. Samuel SK, Minish TM, Davie JR. Altered nuclear matrix protein profiles in oncogene-transformed mouse fibroblasts exhibiting high metastatic potential. Cancer Res. 1997;57:147-51. 